\title{
Singuagens
}

\section{EDIÇÃO FAC-SIMILAR, EDIÇÃO DIPLOMÁTICA E ASPECTOS PALEOGRÁFICOS DE QUATRO MANUSCRITOS REDIGIDOS NO RIO GRANDE DO SUL}

\author{
Débora Spanamberg Wink (UFSM) \\ Tatiana Keller (UFSM)
}

\begin{abstract}
RESUMO: Este trabalho apoia-se na Filologia e na Paleografia para realizar um estudo comparativo entre a ortografia antiga e a atual do português brasileiro. Para atingir este fim, analisaram-se quatro documentos manuscritos, todos redigidos no Rio Grande do Sul e armazenados no Arquivo Histórico Municipal de Santa Maria. O primeiro foi escrito em 1904, enquanto os outros três, em 1910. Tomando como base as edições facsimilares - fotos retiradas do acervo digital do Arquivo Histórico de Santa Maria - e as edições diplomáticas transcrições realizadas segundo as normas de Cambraia (2005) - de cada manuscrito, fizeram-se comentários paleográficos sobre o sistema vocálico (substituições vocálicas), o sistema consonantal (encontros consonantais impróprios, consoantes duplas, substituições consonantais), o uso de diacríticos (principalmente a acentuação), a separação vocabular indevida (hipossegmentação e hipersegmentação), o uso de maiúsculas e o uso de abreviaturas. A principal distinção encontrada foi em relação às regras de uso dos sinais de acentuação.
\end{abstract}

PALAVRAS-CHAVE: Filologia. Manuscritos. Ortografia.

\begin{abstract}
This research, based on Philology and Paleography, aims to develop a comparative study between the ancient Brazilian Portuguese and the current one. In order to do so, four manuscript documents were analyzed, all written in Rio Grande do Sul and stored in the Historical Archive of Santa Maria. The first one was written in 1904, while the other three in 1910. Based on the fac-similar editions - photos taken from the archives of the Historical Archives of Santa Maria - and the diplomatic editions - transcriptions made according to the norms of Cambraia (2005) - from each manuscript, paleographic comments on the vowel system (vowel substitutions), the consonantal system (consonant clusters, geminate consonants, consonant substitutions), the use of diacritics (mainly accentuation), hyposegmentation and hypersegmentation, the use of capital letters and the use of abbreviations. The main distinction found was regarding to the rules of use of the accentuation marks.
\end{abstract}

KEYWORDS: Philology. Manuscripts. Ortography.

\section{INTRODUÇÃO}

Este trabalho consiste em um estudo comparativo entre a ortografia antiga e a atual do português brasileiro, a partir da análise de documentos manuscritos. O corpus constitui-se de quatro documentos, armazenados no Arquivo Histórico Municipal de Santa Maria, todos redigidos no estado do Rio Grande do Sul, um deles em 1904, os outros três em 1910. A análise foi feita com base nas edições fac-similares e diplomáticas de cada manuscrito.

A língua, tanto na fala quanto na escrita, sofre modificações ao longo do tempo: ela tem uma história. A partir deste fato, este trabalho tem por objetivo observar as alterações 


\section{S Linguagens}

pelas quais a língua escrita passou e, consequentemente, cooperar para o conhecimento de sua história. Sobretudo, por se tratar de um trabalho de cunho filológico, também objetiva-se contribuir para a preservação do patrimônio cultural escrito do português brasileiro e para estudos futuros sobre a língua portuguesa.

Além desta Introdução, este trabalho apresenta outras cinco seções: Fundamentação Teórica, Metodologia, Edições, Comentários Paleográficos e Considerações finais. A Fundamentação Teórica explica os objetivos do crítico textual/filólogo e descreve os tipos fundamentais de edição, indicando as vantagens e as desvantagens de cada um. Também apresenta a definição de paleografia e aponta os aspectos paleográficos que serão observados neste trabalho. A seção seguinte, Metodologia, contém a descrição do corpus e a exposição das normas de transcrição adotadas, conforme Cambraia (2005). As edições fac-similares e diplomáticas dos documentos são apresentadas na seção Edições, precedidas por um cabeçalho que contém as seguintes informações: local (onde o documento foi escrito), data (quando o documento foi escrito), cota (onde o documento está arquivado) e tipo de documento. Na seção Comentários Paleográficos, são apresentadas as divergências entre a ortografia antiga e a atual, no que se refere ao sistema vocálico, ao sistema consonantal, ao uso de diacríticos, à separação vocabular, ao uso de maiúsculas e ao uso de abreviaturas. As conclusões são expostas nas Considerações Finais.

\section{FUNDAMENTAÇÃO TEÓRICA}

Spina (1977, p. 20) define a tarefa da Filologia como "o estabelecimento da genuinidade de um texto”. Esta também seria a função da Edótica, porém voltada especificamente para o texto literário. Cambraia (2005, p. 3) conceitua de maneira semelhante os objetivos da Crítica Textual: "a restituição da forma genuína dos textos". Embora estas três áreas, por vezes, confundam-se e suas distinções não sejam tão precisas, Cambraia (2005) destaca as contribuições destas disciplinas para as áreas de estudo que se utilizam do texto: a recuperação, a transmissão e a preservação do patrimônio cultural escrito. Com este fim, o filólogo ou crítico textual pode realizar a edição de documentos - inscrições realizadas em material mole, como o papiro, o papel e o pergaminho (SPINA, 1977).

Linguagens \& Cidadania, v. 19, número especial, jan./dez., 2017. 


\section{S Linguagens}

As formas fundamentais de edição, ou seja, de estabelecimento e de apresentação dos textos, podem ser divididas em dois grandes grupos: o das edições monotestemunhais, em que apenas um testemunho é analisado; e o das edições politestemunhais, em que se comparam diferentes testemunhos de um mesmo texto (CAMBRAIA, 2005).

As edições monotestemunhais dividem-se em quatro tipos: fac-similar, diplomática, paleográfica e interpretativa. A edição fac-similar é a reprodução de um texto sem qualquer alteração, através da fotografia e da xerografia, por exemplo. Neste tipo de edição, o acesso ao documento original é facilitado, porém a compreensão do texto seria possível apenas para especialistas (principalmente em caso de textos bastante antigos). A edição diplomática consiste na transcrição mais fiel possível de um documento, preservando abreviaturas, paragrafação, particularidades linguísticas, etc. A transcrição de um texto facilita sua leitura, mas, justamente porque mantém fielmente as características de um documento, o público a que se destinam as edições diplomáticas ainda seria o mais especializado. A edição paleográfica também consiste na transcrição do texto, porém o crítico textual pode desenvolver abreviaturas, inserir ou suprimir elementos, etc., desde que indique devidamente as alterações. Tornar o texto acessível a um público menos especializado e possibilitar a retificação de equívocos óbvios dos copistas (como a supressão ou a repetição de letras) são as vantagens deste tipo de edição. Por fim, na edição interpretativa, o crítico textual uniformizará graficamente o texto e intervirá nele mais profundamente do que na edição paleográfica. Os especialistas redigem o texto cuidadosamente, procurando, além de tentar aproximar o texto da forma genuína, facilitar a leitura por parte do público.

As edições politestemunhais, por sua vez, são divididas em dois tipos: crítica e genética. Ambos consistem em comparar diversos testemunhos de um mesmo documento, porém os objetivos são distintos. O primeiro tipo pretende, através do confronto de testemunhos geralmente apógrafos, reconstituir o texto na forma final do autor. $\mathrm{O}$ segundo compara documentos geralmente autógrafos e/ou ideógrafos, para registrar as alterações feitas desde as primeiras versões de um texto, até sua finalização.

Para atingir o objetivo de reconstituição de textos, o crítico textual utiliza-se de conhecimentos próprios de outras áreas de estudo. Uma delas é a Paleografia, "estudo das antigas escritas e evolução dos tipos caligráficos em documentos" (SPINA, 1977, p. 18). Esta é a ciência que observará a pontuação, a acentuação, a paragrafação, as abreviaturas, as 


\section{Linguagens \& Cidadania}

separações vocabulares, enfim, as características linguísticas dos textos antigos que se distinguem da escrita atual.

Neste trabalho, serão utilizadas as edições fac-similares e diplomáticas de quatro documentos manuscritos, porque estas conservam o texto original, permitindo a análise ortográfica. Com o objetivo de comparar a escrita antiga e a atual do português brasileiro, este trabalho apresenta observações, na seção Comentários Paleográficos, sobre os seguintes aspectos: o sistema vocálico (substituições vocálicas - u/o, i/e), o sistema consonantal (encontros consonantais impróprios - ct, gn e sç -, consoantes duplas - pp, nn, cc, ff, tt, $11-$, substituições consonantais - z/s, s/z), o uso de diacríticos (principalmente a acentuação), a separação vocabular indevida (hipossegmentação e hipersegmentação), o uso de maiúsculas e o uso de abreviaturas.

\section{METODOLOGIA}

O corpus deste trabalho constitui-se de quatro documentos manuscritos, todos redigidos no estado do Rio Grande do Sul. Os textos serão chamados doravante de Manuscrito A (MA), Manuscrito B (MB), Manuscrito C (MC) e Manuscrito D (MD). A partir deles, analisou-se a ortografia antiga e a atual do português brasileiro.

$\mathrm{O}$ primeiro manuscrito, MA, foi redigido por Antonio Augusto Borges de Medeiros, à época presidente do Rio Grande do Sul, em Porto Alegre, ano de 1904. Os outros três documentos - MB, MC e MD - foram registrados pelo escrivão Abelino Vieira da Silva, em Santa Maria, no ano de 1910.

No MA, o cidadão João Guilherme Weinmann recebe autorização de Antonio Augusto Borges de Medeiros para atuar, por quatro anos, como $1^{\circ}$ suplente de juiz distrital em Santa Maria. O MB descreve uma audiência jurídica, em que se encontram presentes o juiz Antônio Vieira Pires, o réu Elpidio Pereira de Oliveira e as testemunhas Cecilia Moraes, Zeferino Lourenço de Brito e Feliciano Bernardo dos Santos. Primeiramente, as testemunhas são levadas a lugar em que não pudessem ouvir os depoimentos das outras testemunhas e do réu. Depois, o réu é interrogado e as testemunhas inquiridas pelo juiz. No MC, pede-se a um oficial de justiça que intime José Francelino dos Santos, Crescencio Rosa, Clarindo Nunes Pedroso e Antonio Vi[†......] (sobrenome ilegível no documento) para comparecerem na Linguagens \& Cidadania, v. 19, número especial, jan./dez., 2017. 


\section{S Linguagens}

Intendência Municipal, no dia 20 de agosto de 1910. O primeiro intimado seria submetido a um exame de sanidade para averiguar os danos dos ferimentos causados por Antonio Itacotiara; os outros três seriam reinquiridos sobre o mesmo caso. Finalmente, o MD é um termo de recurso em que José Vieira do Amaral recorria do despacho do Juiz de Comarca, que recusou uma denúncia contra o cidadão João Guilherme Weinman (o mesmo do MA). Este teria assumido a função de juiz distrital suplente sem autorização em 1910.

As fotos - edições fac-similares - dos manuscritos foram retiradas do acervo digital do Arquivo Histórico Municipal de Santa Maria, local onde estão armazenados. As transcrições - edições diplomáticas - foram feitas com base nas normas propostas por Cambraia (2005, p. 128-129), reproduzidas abaixo:

a) Caracteres alfabéticos: transcrever como caracteres romanos redondos, reproduzindo-se as diferenças de módulo e dos alógrafos contextuais como no modelo. Quando houver mais de um tipo de caractere no modelo (como, p. ex., capitulares), diferenciá-los na transcrição.

b) Sinais abreviativos: transcrever fielmente.

c) Diacríticos: transcrever fielmente.

d) Sinais de pontuação: transcrever fielmente.

e) Caracteres de leitura duvidosa: transcrever entre parênteses redondos simples ( ).

f) Caracteres de leitura impossível: transcrever como pontos dentro de colchetes precedidos pela cruz † (o número de pontos é o de caracteres não legíveis).

g) Caracteres riscados: transcrever com tachado.

h) Caracteres apagados, modificados, nas entrelinhas ou nas margens: informar em nota.

i) Separação vocabular (intra- $e$ interlinear): reproduzir fielmente.

j) Paragrafação: reproduzir fielmente.

1) Inserções conjecturais: não realizar nenhuma.

m) Supressões conjecturais: não realizar nenhuma.

n) Mudança de fólio, face e coluna: informar na margem de cabeça, em itálico e entre colchetes simples: [ ].

o) Mudanças de punho: informar em nota.

p) Mudanças de tinta: informar em nota.

q) Qualquer outra particularidade: informar em nota.

r) Numeração de linha: inserir na margem externa, contando de 5 em 5 , de forma contínua em todo o texto.

A partir da transcrição, foram feitos comentários paleográficos sobre o sistema vocálico (substituições vocálicas - u/o, i/e), o sistema consonantal (encontros consonantais impróprios - ct, gn e sç -, consoantes duplas - pp, nn, cc, ff, tt, ll -, substituições consonantais $-\mathrm{z} / \mathrm{s}$, s/z), o uso de diacríticos (principalmente a acentuação), a separação 


\section{Linguagens W E Cidadania}

vocabular (hipossegmentação e hipersegmentação), o uso de maiúsculas e o uso de abreviaturas.

\section{EDIÇÕES}

Nas páginas seguintes, são apresentadas as edições fac-similar e diplomática de cada um dos manuscritos em estudo, precedidas por um cabeçalho que contém as seguintes informações: local (onde o documento foi escrito), data (quando o documento foi escrito), cota (onde o documento está arquivado) e tipo de documento.

\section{Edição Fac-similar do Manuscrito A}

LOCAL: Porto Alegre, Rio Grande do Sul, Brasil

DATA: 30 de novembro de 1904

COTA: Arquivo Histórico Municipal de Santa Maria

TIPO DE DOCUMENTO: Nomeação de cargo 


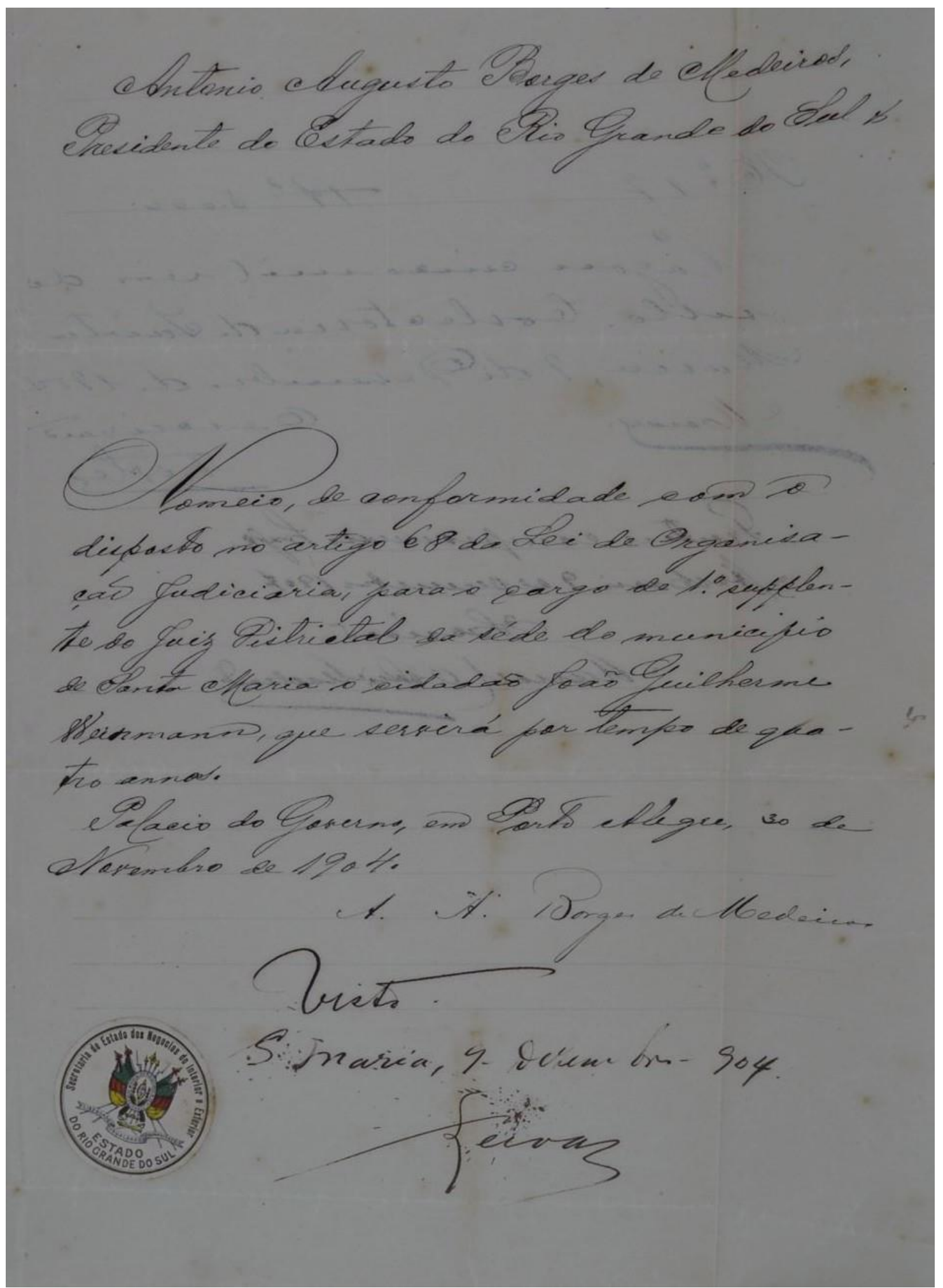

Figura 1: Fac-símile do manuscrito A. Fonte: Arquivo Histórico de Santa Maria.

Linguagens \& Cidadania, v. 19, número especial, jan./dez., 2017. 


\section{Linguagens \& Cidadania}

\section{Edição Diplomática do Manuscrito A}

Antonio Augusto Borges de Medeiros, Presidente do Estado do Rio Grande do Sul

Nomeio, de conformidade com o

5 disposto no artigo 68 da Lei de Organisaçaõ Judiciaria, para o cargo de $1^{\circ}$ supplente do Juiz Districtal da séde do município de Santa Maria o cidadaõ João Guilherme Weinmann, que servirá por tempo de qua-

10 tro annos.

Palacio do Governo, em Porto Alegre, 30 de Novembro de 1904.

A. A. Borges de Medeiros

15 Visto $^{1}$

S. Maria, 9 - Dezembro - $904^{2}$. [assinatura $^{3}$

Edição Fac-similar do Manuscrito B

\begin{tabular}{|l|}
\hline LOCAL: Santa Maria, Rio Grande do Sul, Brasil \\
\hline DATA: 31 de maio de 1910 \\
\hline COTA: Arquivo Histórico Municipal de Santa Maria \\
\hline TIPO DE DOCUMENTO: Termo de audiência \\
\hline
\end{tabular}

\footnotetext{
${ }^{1}$ A partir daqui, houve mudança de punho.

${ }^{2}$ Supõe-se que seja 1904. Aparentemente, o primeiro algarismo não foi grafado.

3 À esquerda, há uma figura colorida com o símbolo do estado do Rio Grande do Sul, com os dizeres: Secretaria do Estado dos Negocios do Interior e Exterior. ESTADO DO RIO GRANDE DO SUL. Não é possível definir quando esta figura foi colocada no documento.
}

Linguagens \& Cidadania, v. 19, número especial, jan./dez., 2017. 


\section{Linguagens \& Cidadania}

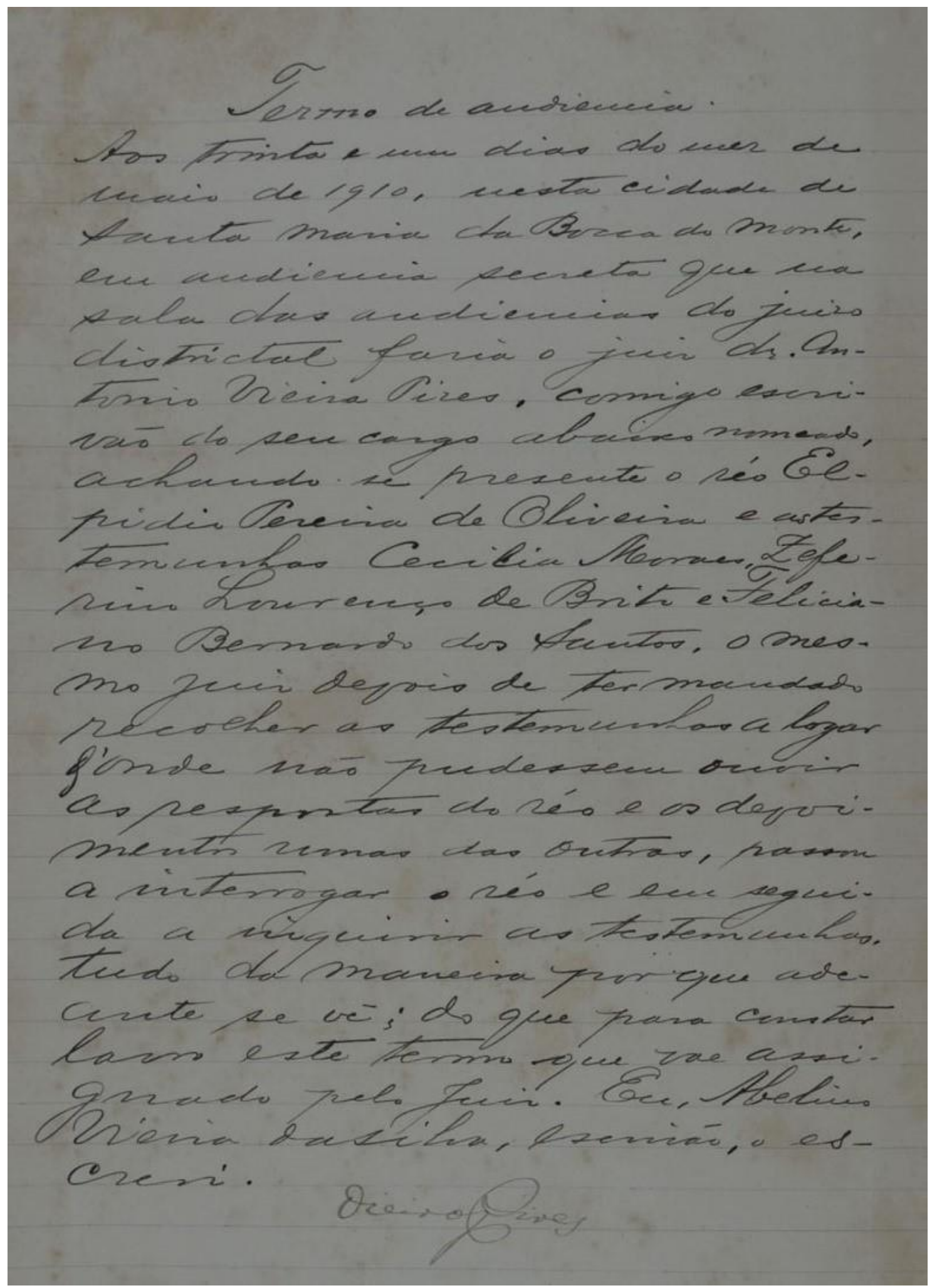

Figura 2: Fac-símile do manuscrito B. Fonte: Arquivo Histórico de Santa Maria.

Linguagens \& Cidadania, v. 19, número especial, jan./dez., 2017. 


\section{Linguagens \& Cidadania}

\section{Edição Diplomática do Manuscrito B}

Termo de audiencia. Aos trinta e um dias do mez de Maio de 1910, nesta cidade de Santa Maria da Bocca do Monte,

5 em audiencia secreta que na sala das audiencias do juizo districtal faria o juiz dr. Antonio Vieira Pires, comigo escrivão do seu cargo abaixo nomeado,

10 achando-se presente o réo Elpidio Pereira de Oliveira e astestemunhas Cecilia Moraes, Zeferino Lourenço de Brito e Feliciano Bernardo dos Santos, o mes-

15 mo Juiz depois de ter mandado recolher as testemunhas a logar d'onde não pudessem ouvir as respostas do réo e os depoimentos umas das outras, passou

20 a interrogar o réo e em seguida a inquirir as testemunhas, tudo da maneira porque adeante se vê; do que para constar lavro este termo que vae assi-

25 gnado pelo Juiz. Eu, Abelino Vieira dasilva, o escrivão, o escrevi.

VieiraPires

\section{Edição Fac-similar do Manuscrito C}

LOCAL: Santa Maria, Rio Grande do Sul, Brasil

DATA: 16 de agosto de 1910

COTA: Arquivo Histórico Municipal de Santa Maria

TIPO DE DOCUMENTO: Mandado de intimação

Linguagens \& Cidadania, v. 19, número especial, jan./dez., 2017. 


\section{Linguagens \& Cidadania}

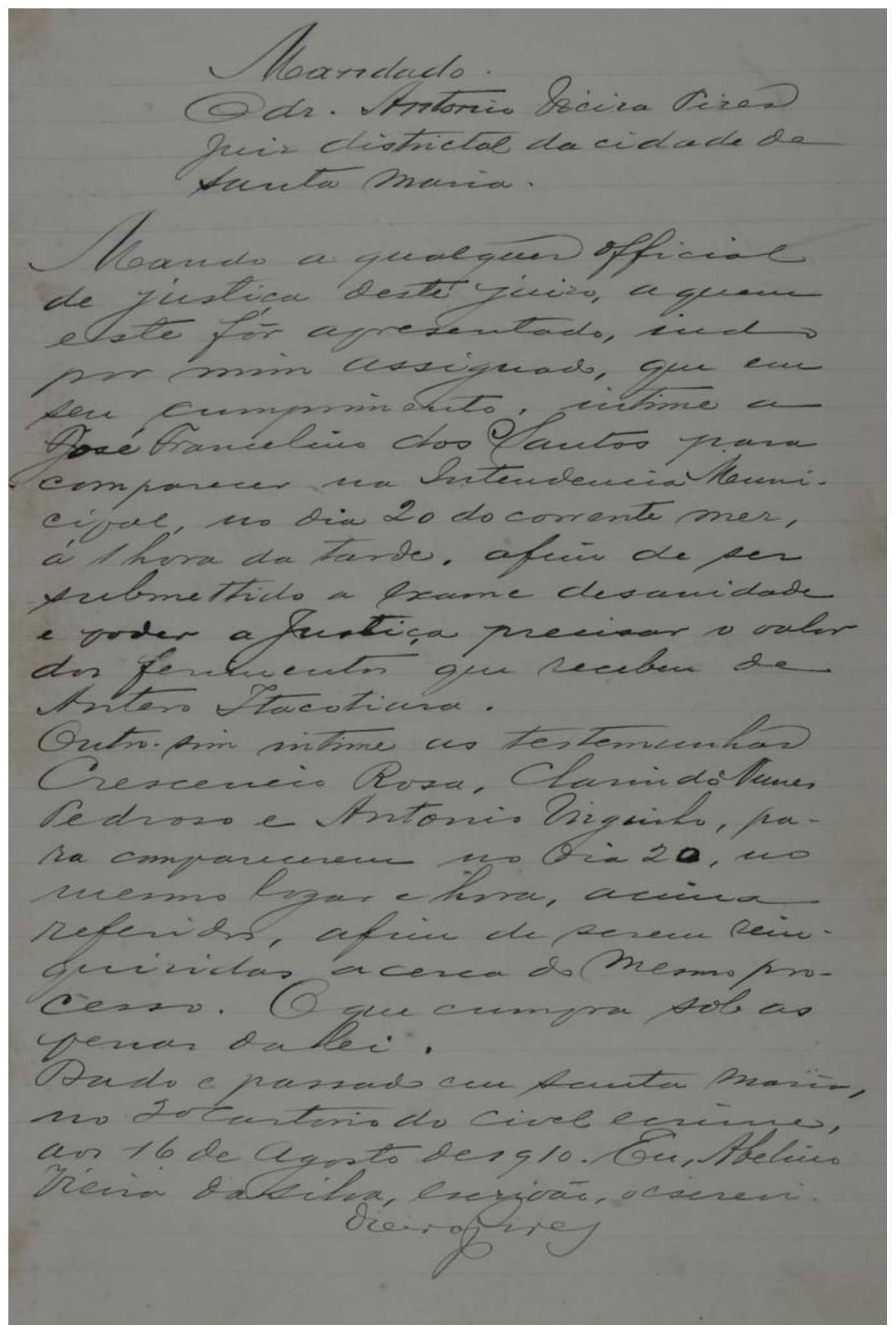

Figura 3: Fac-símile do manuscrito C. Fonte: Arquivo Histórico de Santa Maria.

Linguagens \& Cidadania, v. 19, número especial, jan./dez., 2017. 
Edição Diplomática do Manuscrito C

Mandado.

$\mathrm{O}$ dr. Antonio Vieira Pires

Juiz districtal da cidade de

Santa Maria.

5

Mando a qualquer official

de justiça deste juizo, a quem

este fôr apresentado, indo

por mim assignado, que em

10 seu cumprimento, intime a

José Francelino dos Santos para

comparecer na Intendencia Muni-

cipal, no dia 20 do corrente mez,

à 1 hora da tarde, afim de ser

15 submettido a exame desanidade

e poder a Justiça precisar o valor

dos ferimentos que recebeu de

Antero Itacotiara.

Outro-sim intime as testemunhas

20 Crescencio Rosa, Clarindo Nunes

Pedroso e Antonio Vi[†...... $]^{4}$, pa-

ra comparecem no dia 20 , no

mesmo logar e hora, acima

referidos, afim de serem rein-

25 quiridas acerca do mesmo pro-

cesso. O que cumpra sob as

penas dalei.

Dado e passado em Santa Maria,

no $2^{\circ}$ cartorio do civel ecrime,

30 aos 16 de Agosto de1910. Eu, Abelino

Vieira dasilva, escrivão, o escrevi.

VieiraPires

\footnotetext{
${ }^{4}$ A cruz (†) sinaliza um ponto do documento que foi considerado de leitura impossível. O número de pontos (.) subsequentes corresponde ao número de letras do manuscrito que não puderam ser decifradas.
}

Linguagens \& Cidadania, v. 19, número especial, jan./dez., 2017. 


\section{Linguagens \& Cidadania}

\section{Edição Fac-similar do Manuscrito D}

\begin{tabular}{|l|}
\hline LOCAL: Santa Maria, Rio Grande do Sul, Brasil \\
\hline DATA: 15 de março de 1910 \\
\hline COTA: Arquivo Histórico Municipal de Santa Maria \\
\hline TIPO DE DOCUMENTO: Termo de recurso \\
\hline
\end{tabular}

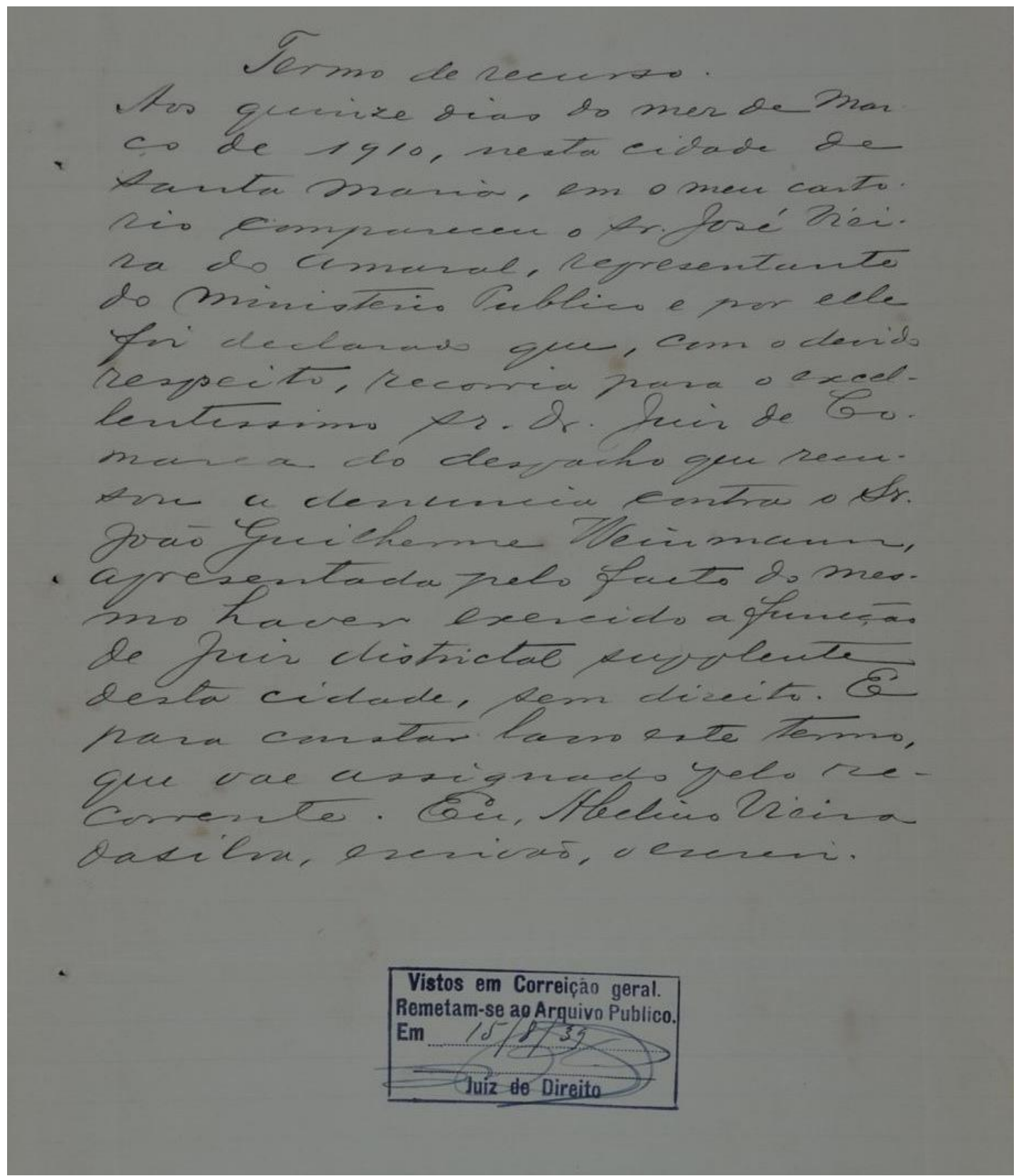

Figura 4: Fac-símile do manuscrito D. Fonte: Arquivo Histórico de Santa Maria.

Linguagens \& Cidadania, v. 19, número especial, jan./dez., 2017. 


\section{S Linguagens}

\section{Edição Diplomática do Manuscrito D}

Termo de recurso.

Aos quinze dias do mez de Março de 1910, nesta cidade de Santa Maria, em o meu carto-

5 rio compareceu o sr. José Vieira do Amaral, representante do Ministerio Publico e por elle foi declarado que, com o devido respeito, recorria para o excel-

10 lentissimo sr. dr. Juiz de Comarca do despacho que recusou a denuncia contra o $\mathrm{Sr}$. João Guilherme Weinmann, apresentada pelo facto do mes-

15 mo haver exercido a função de Juiz districtal suplente desta cidade, sem direito. E para constar lavro este termo, que vae assignado pelo re-

20 corrente. Eu, Abelino Vieira dasilva, escrivão, o escrevi.

Vistos em Correição geral. ${ }^{5}$

Remetam-se ao Arquivo Publico.

25 Em 15/9/39

[assinatura]

Juiz de Direito

\section{COMENTÁRIOS PALEOGRÁFICOS}

Com base nos pressupostos da Paleografia, nesta seção são expostas as divergências entre a ortografia atual e a antiga do português brasileiro, de acordo com o que foi observado nos documentos em questão. A seguir, analisa-se o sistema vocálico (substituições vocálicas u/o, i/e), o sistema consonantal (encontros consonantais impróprios - ct, gn e sç -, consoantes

\footnotetext{
${ }^{5}$ A partir daqui, transcreve-se as escritas de um carimbo, com exceção da data e da assinatura, que foram grafadas à mão.
}

Linguagens \& Cidadania, v. 19, número especial, jan./dez., 2017. 


\section{Linguagens \& Cidadania}

duplas - pp, nn, cc, ff, tt, 11 -, substituições consonantais - z/s, s/z), o uso de diacríticos (principalmente a acentuação), a separação vocabular indevida (hipossegmentação e hipersegmentação), o uso de maiúsculas e o uso de abreviaturas.

\subsection{Sistema vocálico}

\subsubsection{Substituições vocálicas}

A substituição vocálica consiste no uso de uma vogal no lugar de outra. Foram encontradas ocorrências com as palavras réo > réu, ade(-)ante > adiante, vae > vai, logar > lugar e civel > civil, reproduzidas no quadro abaixo.

Quadro 1: Substituições vocálicas

\begin{tabular}{|l|l|l|l|}
\hline DOCUMENTO & PALAVRA & FAC-SÍMILE & SUBSTITUIÇÃO \\
\hline MB & Réo & $\begin{array}{l}\text { séo } \\
\text { ante- }\end{array}$ & $u$ por $o$ \\
\hline MB & Vae & $i$ por $e$ \\
\hline MB, MD & Logar & rece & $i$ por $e$ \\
\hline MB, MC & Cível & ceree & $i$ por $e$ \\
\hline MC & cer $o$ & \\
\hline
\end{tabular}

\subsection{Sistema consonantal}

\subsubsection{Encontros consonantais impróprios}

Segundo Donadel (2007), encontros consonantais impróprios consistem em grupos consonantais que não são formados por obstruinte mais líquida, como a palavra "advogado". Foram observadas ocorrências com as palavras districtal > distrital, assignado > assinado, facto $>$ fato e funcção > função, como mostra o Quadro 2.

Quadro 2: Encontros consonantais impróprios

\begin{tabular}{|l|l|l|l|}
\hline DOCUMENTO & PALAVRA & FAC-SÍMILE & ENCONTRO \\
\hline
\end{tabular}

Linguagens \& Cidadania, v. 19, número especial, jan./dez., 2017. 


\section{Linguagens \& Cidadania}

\begin{tabular}{|c|c|c|c|}
\hline $\begin{array}{l}\text { MA, MB, MC, } \\
\text { MD }\end{array}$ & Districtal & Dilnielab & $c t$ \\
\hline $\mathrm{MB}, \mathrm{MC}, \mathrm{MD}$ & assignado & cheviguad, & $g n$ \\
\hline $\mathrm{MD}$ & facto & 4 & $c t$ \\
\hline $\mathrm{MD}$ & funcção & & $c c ̧$ \\
\hline
\end{tabular}

\subsubsection{Consoantes duplas}

Consiste na duplicação de consoantes, que, atualmente, não são duplicadas. Conforme se observa no Quadro 3, foram encontradas ocorrências com as palavras supplente > suplente, annos > anos, Bocca > Boca, official > oficial, submettido > submetido, elle > ele e excellentissimo > excelentíssimo.

Quadro 3: Consoantes duplas

\begin{tabular}{|c|c|c|c|}
\hline DOCUMENTO & PALAVRA & FAC-SÍMILE & CONSOANTE \\
\hline MA, MD & supplente & levite & $p p$ \\
\hline MA & annos & and & $n n$ \\
\hline MB & Bocca & Ore. & $c c$ \\
\hline $\mathrm{MC}$ & official & & $f f$ \\
\hline $\mathrm{MC}$ & submettido & 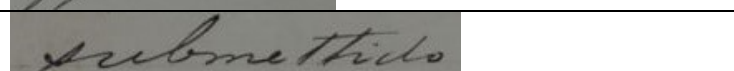 & $t t$ \\
\hline MD & elle & ecle & $l l$ \\
\hline MD & $\begin{array}{l}\text { excel- } \\
\text { lentissimo }\end{array}$ & el-levter..mu & $l l$ \\
\hline
\end{tabular}

\subsubsection{Substituições consonantais}

A substituição consonantal consiste no uso de uma consoante no lugar de outra. Foram encontradas ocorrências com as palavras organisaçaõ > organização e mez > mês, conforme reproduzido abaixo, no Quadro 4.

Quadro 4: Substituições consonantais

Linguagens \& Cidadania, v. 19, número especial, jan./dez., 2017. 


\section{Linguagens \\ r. \& Cidadania}

\begin{tabular}{|l|l|l|l|}
\hline DOCUMENTO & PALAVRA & FAC-SÍMILE & SUBSTITUIÇÃO \\
\hline MA & $\begin{array}{l}\text { Organisa- } \\
\text { çaõ }\end{array}$ & sor $s$ \\
MB, MC, MD & mez & szer & $s$ por $z$ \\
\hline
\end{tabular}

\subsection{Diacríticos}

Diacríticos (CAMBRAIA, 2005) ou notações léxicas (CUNHA e CINTRA, 2013) são sinais da língua portuguesa escrita, que, atualmente, servem para auxiliar na pronúncia de uma palavra. Cambraia (2005) destaca que, no que se refere à escrita antiga, é possível que os diacríticos fossem empregados por motivos distintos dos atuais, ou mesmo que não seja possível precisar o valor de uma notação léxica. Não é o caso dos documentos analisados neste trabalho. Cunha e Cintra (2013) apontam o acento, o til, o trema, o apóstrofo, a cedilha e o hífen como os diacríticos atuais.

A seguir, o uso de diacríticos é explicado conforme as orientações desses autores.

Para indicar o acento, utilizam-se os sinais de acentuação, que podem ser agudo ('), circunflexo $\left({ }^{\wedge}\right)$ e grave $\left({ }^{`}\right)$. O primeiro assinala as vogais tônicas fechadas $i$ e $u$ e as vogais tônicas abertas e semiabertas $a, e$ e $o$. O acento circunflexo indica o timbre semifechado das tônicas $a, e$ e $o$. Emprega-se o acento grave para mostrar a ocorrência de crase.

O til ( ) é utilizado para indicar a nasalidade das vogais $a$ e $o$. O trema (") não é empregado atualmente na grafia da língua portuguesa, de acordo com o Acordo Ortográfico de 2009. O apóstrofo (') assinala a supressão de um fonema. A cedilha (_) é um sinal colocado abaixo da letra $c$, antes das vogais $a, o$ e $u$, para representar o fonema /s/. O hífen (-) é usado para ligar elementos de palavras compostas ou derivadas por prefixação, para unir pronomes átonos a verbos e para translinear uma sílaba.

Ocorrências de trema não foram encontradas nos documentos em análise. A utilização do cedilha e do til foi equivalente à atual, como em funcção

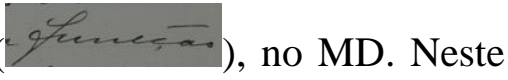

mesmo documento, foi utilizado apóstrofe na palavra d'onde (Giszde). O uso do diacrítico, neste caso, suprime o fonema /e/ de "de" - em concordância com a definiç̧ão de 


\section{Linguagens \& Cidadania}

Cunha e Cintra (2013) -, porém, atualmente, esta palavra é grafada sem o apóstrofe: “donde".

O hífen foi usado em uma hipersegmentação no MC: outro-sim (Qut to - pim ); nos demais casos, o uso também foi equivalente ao uso atual, como na separação da palavra Muni(-)cipal (Heani- cifoes, no MC.

$\mathrm{O}$ aspecto mais divergente foi o uso dos acentos: houve distinção quanto às regras de acentuação de palavras - com exceção do acento grave, cuja única ocorrência, no MC, indicou crase: à ( $a^{\prime}$ ); e do uso do acento agudo nos casos de servirá (cersèr - $)$, no MA, e de réo ( séo), "réu", no MB.

\subsubsection{Regras de acentuação}

De acordo com Câmara Jr (2001, p. 63), o acento é "uma maior força expiatória, ou intensidade de emissão, da vogal de uma sílaba em contraste com as demais vogais silábicas. Ele pode incidir na última, penúltima, antepenúltima, ou mais raramente, quarta última de um vocábulo fonológico".

Em língua portuguesa, as palavras podem ser oxítonas (acento tônico na última sílaba), paroxítonas (acento tônico na penúltima sílaba) e proparoxítonas (acento tônico na antepenúltima sílaba). Serão descritas abaixo, com base em Cunha e Cintra (2013), as regras atuais de acentuação que não foram seguidas nos manuscritos analisados.

As palavras oxítonas recebem acento circunflexo quando terminadas em $e$ e $o$ semifechados, seguidos ou não de $s$. A mesma regra vale para os monossílabos tônicos, como "mês”, grafado sem acento em MB, MC e MD: mez (žę).

Quanto às paroxítonas, acentuam-se os vocábulos terminados em ditongos vocálicos crescentes, caso de palavras como "ciência", "prioritário", “malária” e “água". Nos manuscritos analisados, todavia, vocábulos desta natureza não receberam sinais de acentuação, como se pode observar no Quadro 5.

Quadro 5: Acentuação das paroxítonas

\begin{tabular}{|l|l|l|}
\hline DOCUMENTO & PALAVRA & FAC-SÍMILE \\
\hline
\end{tabular}

Linguagens \& Cidadania, v. 19, número especial, jan./dez., 2017. 


\section{$\checkmark$ Linguagens \& Cidadania}

\begin{tabular}{|c|c|c|}
\hline $\mathrm{MA}$ & Judiciaria & 2 \\
\hline MA & municipio & \\
\hline MA & Palacio & \\
\hline $\mathrm{MB}$ & audiencia & acedrer \\
\hline $\mathrm{MC}$ & Intendencia & 2 \\
\hline $\mathrm{MC}$ & $2^{\circ}$ cartorio & Jol \\
\hline $\mathrm{MD}$ & Ministerio & Mnine \\
\hline $\mathrm{MD}$ & denuncia & $c<$ \\
\hline
\end{tabular}

Atualmente, todos os vocábulos proparoxítonos são assinalados com acento. Utiliza-se o acento agudo quando a vogal tônica for $a$ aberta, $e$ ou $o$ semiabertas. Portanto, as palavras

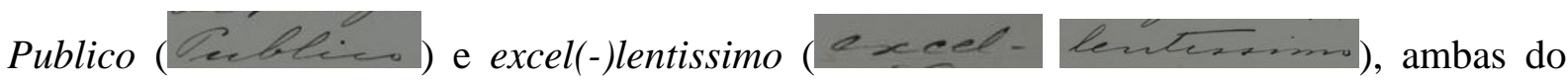
MD, deveriam receber acento agudo, mas não recebem: "Público" e “excelentíssimo".

Além disso, também recebem acento agudo o $i$ e $u$ tônicos que formam hiato. É o motivo pelo qual juizo (cicé, , presente em MB e MC, deveria receberia o acento: “juízo”.

Câmara Jr (2001, p. 64) destaca que "o acento em português é também distintivo, pois serve pela sua posição a distinguir palavras". O vocábulo "sede" (local onde um estabelecimento situa-se) é grafado igual à palavra "sede" (vontade de beber água), e ambas as palavras são substantivos. Assim, o que as distingue é o timbre das vogais tônicas, embora nenhuma das duas receba notação léxica atualmente: no primeiro caso, o $e$ tônico é aberto, e, no segundo, é fechado. O autor do MA, provavelmente, utilizou o acento agudo em séde (éde) para assinalar esta diferença de pronúncia e, consequentemente, de significado.

No MC, houve uso de acento circunflexo na palavra "for" (verbo): fôr ( um caso de acento distintivo - como entre as palavras "por" (preposição) e "pôr" (verbo). Provavelmente, o diacrítico foi utilizado para assinalar a pronúncia semifechada da vogal $o$.

\subsection{Separação vocabular indevida}

Linguagens \& Cidadania, v. 19, número especial, jan./dez., 2017. 


\section{Linguagens \& Cidadania}

A seguir, serão listados os casos de hipossegmentação, em que a separação vocabular não acontece, mas deveria, como se vê no Quadro 6.

Quadro 6: Hipossegmentação

\begin{tabular}{|c|c|c|c|}
\hline DOCUMENTO & PALAVRA & FAC-SÍMILE & SEPARAÇÃO \\
\hline $\mathrm{MB}$ & $\begin{array}{l}\text { astes- } \\
\text { temunhas }\end{array}$ & & as testemunhas \\
\hline $\mathrm{MB}, \mathrm{MC}, \mathrm{MD}$ & dasilva & & da Silva \\
\hline MC & desanidade & Clescuridabe & de sanidade \\
\hline $\mathrm{MC}$ & dalei & d a lle & da lei \\
\hline $\mathrm{MC}$ & $2^{\circ}$ cartorio & $y=2$ & $2^{\circ}$ cartorio \\
\hline $\mathrm{MC}$ & ecrime & - & e crime \\
\hline $\mathrm{MC}$ & de1910 & $8 c$ & de 1910 \\
\hline
\end{tabular}

No MC, encontra-se o único caso de hipersegmentação - separação vocabular acontece indevidamente - observado nos documentos analisados: Outro-sim Qutro- arin,), em oposição ao atual "outrossim".

\subsection{Abreviaturas}

Spina (1977) classifica as abreviaturas em: abreviatura por siglas, abreviatura por apócope, abreviatura por síncope, abreviatura por letras sobrepostas, abreviatura por signos especiais de abreviação e letras numerais. Dentre estas, porém, só foram encontradas duas abreviaturas por sigla (em que apenas a letra inicial é representada) e duas por síncope (em que elementos do meio do vocábulo são suprimidos) nos documentos em análise, reproduzidas no Quadro 7.

Quadro 7: Abreviaturas

\begin{tabular}{|l|l|l|l|l|}
\hline DOCUMENTO & PALAVRA & FAC-SÍMILE & SIGNIFICADO & TIPO \\
\hline MA & A. & & Antonio & Sigla \\
& & & & \\
\hline
\end{tabular}

Linguagens \& Cidadania, v. 19, número especial, jan./dez., 2017. 


\section{Linguagens \& Cidadania}

\begin{tabular}{|l|l|l|l|l|}
\hline MA & A. & & Augusto & Sigla \\
\hline MB, MC, MD & dr. & & Doutor & Síncope \\
\hline MD & sr. & & Senhor & Síncope \\
\hline
\end{tabular}

\subsection{Uso de maiúsculas}

Diferentemente da ortografia atual, os meses do ano foram escritos com inicial maiúscula: Novembro (MA), Dezembro (MA), Maio (MB), Agosto (MC), Março (MD). Além dos meses, o cargo de juiz também foi grafado com a inicial maiúscula: Juiz (MB) e Juiz de Comarca (MD). O cargo de "juiz districtal” foi grafado como Juiz Districtal no MA e como Juiz districtal no MC e no MD. Nos três documentos que redigiu, Abelino Vieira da Silva grafou seu último sobrenome sem maiúscula nem separação vocabular: dasilva (MB, MC e MD).

\subsection{Pontos de dificuldade de leitura e soluções adotadas}

No MA, houve dúvida quando ao uso do til na sílaba final de Organisa(-)çã̃ (

> Organização. A questão era se o diacrítico estava sendo utilizado na letra $o$, na $a$ ou em ambas. Posteriormente, o manuscrito traz a palavra cidadaõ ( weci las $)>$ cidadão, em que se percebe mais claramente o uso do til no $o$ final. Portanto, deduziu-se que o diacrítico pertencia à vogal final.

Também se questionou acerca da locução verbal ter mandado do MB. Estas duas palavras estão grafadas praticamente juntas, de modo que não seria estranho considerá-las um caso de hipossegmentação. Porém, segundo Câmara Jr (2011, p. 63), a presença do acento "assinala a existência de um vocábulo", e a tendência é que elementos átonos juntem-se a elementos tônicos. Como ter e mandado são duas formas verbais, ambas são formas tônicas, não sendo comum sua união em uma única palavra. É diferente do que acontece em astes(-)temunhas

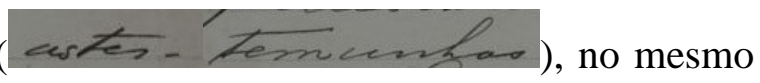

Linguagens \& Cidadania, v. 19, número especial, jan./dez., 2017. 


\section{S Linguagens}

documento, em que um elemento átono (artigo as) junta-se a um elemento tônico (substantivo testemunhas). Por essas razões, ter mandado não foi considerado um caso de hipossegmentação.

A palavra fôr ( $\left.f^{\prime \prime}\right)>$ for do MC foi outro caso que gerou dúvidas. O diacrítico foi assinalado com uma linha reta, o que dificultou a distinção deste sinal entre acento agudo, acento circunflexo ou til. Não houve outra situação tão peculiar entre os manuscritos analisados, portanto não foi possível transcrever com base em comparação. Este verbo, segundo as normas atuais, não recebe nenhum sinal de acentuação. Para decifrar a notação léxica, utilizaram-se as definições apontadas por Cunha e Cintra (2013), o que levou à conclusão de que o diacrítico é um acento circunflexo que assinala a pronúncia semifechada de $o$, já que a pronúncia desta vogal, nesse verbo, não é aberta nem nasalizada.

No mesmo documento, a palavra submettido (Lebme thiclo) > submetido gerou dúvida: seria uma consoante dupla ou um caso de uso do th? Comparando com os outros manuscritos registrados pelo mesmo escrivão, verifica-se a duplicação de consoantes em várias palavras (conforme listado na subseção 5.2.2.), mas não há utilização de th em nenhuma delas. Assim, adotou-se a forma submettido por coerência ao estilo do autor. Entretanto, também é possível argumentar que a transcrição correta seja submethido.

Ainda no $\mathrm{MC}$, não foi possível transcrever o sobrenome no sintagma Antonio $\operatorname{Vi}[\dagger \ldots . . .$. (Astóni: Digsicho). A grafia sugere Viguinho, Virguilo, etc, mas não foi possível encontrar o sobrenome correto, e, por ser um nome próprio, é muito difícil decifrar por conjectura. Por isso, consideraram-se os caracteres finais como de leitura impossível.

Outro caso em que se levou em conta o estilo do autor foi em o escrevi (oczeci), também no MC. Aparentemente, seria um caso de hipossegmentação, levando-se em conta a proximidade das letras. Além disso, por $o$ ser uma palavra átona e escrevi uma palavra tônica, a união entre ambas seria possível. Todavia, como o autor de MB, MC e MD finaliza os documentos da mesma forma ${ }^{6}$, concluiu-se que não seria um caso de hipossegmentação.

\footnotetext{
${ }^{6}$ Eu, Abelino Vieira dasilva, escrivão, o escrevi.
} 


\section{S Linguagens}

A única ocorrência de crase não foi reconhecida à primeira vista, porque o acento grave está inclinado para a direita, assemelhando-se ao acento agudo. Entretanto, pelo contexto (indicação de hora), só poderia ser crase. Além disso, a inclinação do diacrítico segue o estilo de escrita do autor, cujas letras também são inclinadas à direita: à (á).

Outro ponto de dificuldade foi a grafia do último sobrenome de Abelino Vieira da Silva, escrivão dos documentos $\mathrm{MB}$, MC e MD. Como mostrado na subseção 5.4.1, o escrivão tende a realizar hipossegmentações (total de 7 ocorrências). Quando assina os manuscritos, Abelino une os últimos elementos de seu sobrenome em uma única palavra: "dasilva". Não só os une, como coloca ambos com letra minúscula, o que causou estranheza pelo fato de ser o nome do próprio escrivão. Porém, através da comparação com o $d$ e com o $s$ do autor em outras palavras, não há dúvidas de que ele redigiu seu último nome como dasilva

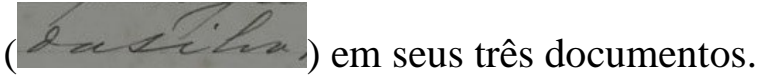

Duas situações causaram dificuldade quanto a sua classificação: em $o$ meu

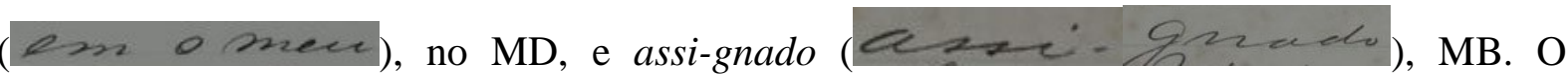
primeiro não é um caso de hipersegmentação, é apenas o uso de "no" antes da elisão (em + o). O segundo é uma separação silábica com encontro consonantal impróprio (gn) e consoante muda, diferente da fragmentação, por exemplo, da palavra "ritmo", em que $t$ é pronunciado: "rit-mo". Assim, também não se pode falar em hipersegmentação ou qualquer outro "erro" de grafia: como $g$ não é pronunciado, sua colocação na separação silábica é indiferente. Ambas são registro de uso da ortografia distinto da atual.

\section{CONSIDERAÇÕES FINAIS}

A partir das edições fac-similares e diplomáticas de quatro documentos manuscritos, foi possível observar divergências entre a ortografia antiga e a atual do português brasileiro. As edições fac-similares foram retiradas do acervo digital do Arquivo Histórico Municipal de Santa Maria, e a transcrição foi feita com base em Cambraia (2005). Optou-se por realizar estes dois tipos de edição, porque são os tipos que mais preservam o texto original, permitindo, assim, a análise ortográfica. Apoiando-se na Filologia e na Paleografia, este trabalho buscou contribuir para o conhecimento da história do português brasileiro, para a

Linguagens \& Cidadania, v. 19, número especial, jan./dez., 2017. 


\section{S Linguagens}

preservação do patrimônio cultural escrito no Brasil e para estudos futuros sobre língua e ortografia portuguesas.

Com relação ao sistema vocálico, houve substituições de $i$ por $e$ e de $u$ por $o$. O sistema consonantal apresentou encontros consonantais impróprios ( $c t$, gn e $c c$ ), duplicação de consoantes ( $p p, n n, c c, f f, t t$ e $l l$ ) e substituições de $z$ por $s$ e de $s$ por $z$. Quanto aos diacríticos, o uso do til, do trema, do apóstrofo, da cedilha e do hífen não se distinguiu do uso atual. O uso dos acentos, entretanto, distinguiu-se bastante no que se refere às regras de acentuação contemporâneas: o monossílabo tônico "mês" (MB, $\mathrm{MC}$ e $\mathrm{MD}$ ) não recebeu acento circunflexo; as palavras paroxítonas terminadas em ditongo vocálico crescente e as proparoxítonas não foram assinaladas com diacrítico; o $i$ tônico que forma hiato em "juízo" (MB, MC) também não foi acentuado. Além disso, observou-se o uso incomum de acento em séde (MA) e fôr (MC). Na separação vocabular, predominaram as ocorrências de hipossegmentação. As abreviaturas foram do tipo por síncope e por sigla, cada uma ocorrendo duas vezes. Por fim, a utilização de maiúsculas aconteceu com os meses do ano e com alguns cargos públicos, e não ocorreu na grafia do sobrenome dasilva.

\section{REFERÊNCIAS}

CÂMARA Jr., J. M. Estrutura da língua portuguesa. 34. ed. Petrópolis: Vozes, 2001.

CAMBRAIA, C. N. Introdução à crítica textual. São Paulo: Martins Fontes, 2005.

CUNHA, C.; CINTRA, L. Nova gramática do português contemporâneo. 6. ed. Rio de Janeiro: Lexikon, 2013.

DONADEL, G. Grupos consonantais impróprios: estudo diacrônico com base em gramáticas. 2007. 130f. Dissertação (Mestrado em Teoria e Análise Linguística) - Instituto de Letras, Universidade Federal do Rio Grande do Sul, Rio Grande do Sul. 2007.

SPINA, S. Introdução à edótica: crítica textual. São Paulo: Cultrix, EDUSP, 1977. 